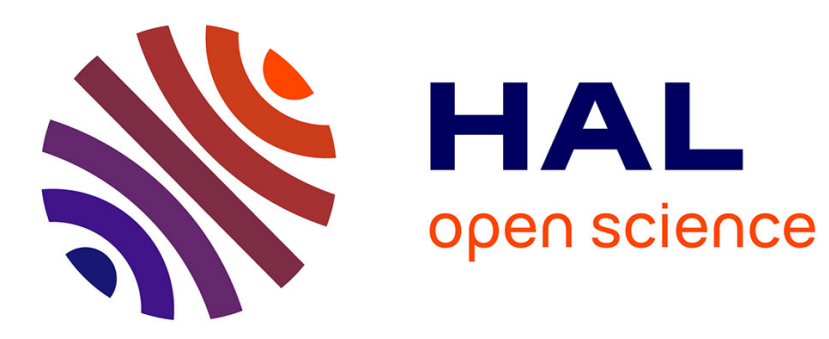

\title{
Anodic Stability of New Sulfone-Based Electrolytes for Lithium-Ion Batteries
}

\author{
Benjamin Flamme, Mansour Haddad, Phannarath Phansavath, Virginie \\ Ratovelomanana-Vidal, Alexandre Chagnes
}

\section{To cite this version:}

Benjamin Flamme, Mansour Haddad, Phannarath Phansavath, Virginie Ratovelomanana-Vidal, Alexandre Chagnes. Anodic Stability of New Sulfone-Based Electrolytes for Lithium-Ion Batteries. ChemElectroChem, 2018, 5 (16), pp.2279-2287. 10.1002/celc.201701343 . hal-02182970

\section{HAL Id: hal-02182970 \\ https://hal.univ-lorraine.fr/hal-02182970}

Submitted on 20 Aug 2019

HAL is a multi-disciplinary open access archive for the deposit and dissemination of scientific research documents, whether they are published or not. The documents may come from teaching and research institutions in France or abroad, or from public or private research centers.
L'archive ouverte pluridisciplinaire HAL, est destinée au dépôt et à la diffusion de documents scientifiques de niveau recherche, publiés ou non, émanant des établissements d'enseignement et de recherche français ou étrangers, des laboratoires publics ou privés. 


\title{
Anodic stability of new sulfone-based electrolytes for lithium-ion batteries
}

\author{
Benjamin Flamme, ${ }^{[b]}$ Mansour Haddad, ${ }^{[b]}$ Phannarath Phansavath, ${ }^{[b]^{*}}$ Virginie Ratovelomanana- \\ Vidal, ${ }^{[b]^{*}}$ and Alexandre Chagnes ${ }^{*[a]}$
}

Twenty-two new bifunctional sulfones containing ester, ether and carbonate moieties have been synthesized in the present work Their physicochemical properties (dynamic viscosity, ionic conductivity in the presence of lithium bistrifluoromethanesulfonimidate (LiTFSI), boiling and melting points) and their anodic stability have been investigated. Major drawbacks for the use of these sulfones in Lithium Batteries (LiBs) are their high viscosities and high melting points. Nevertheless, these solvents exhibit high anodic stability at platinum, glassy carbon and NMC $\left(\mathrm{LiNi}_{1 / 3} \mathrm{Mn}_{1 / 3} \mathrm{Co}_{1 / 3}\right)$ electrodes and their ionic conductivities in the presence of LiTFSI remain high enough to envisage their use in LiBs despite their high viscosities. In particular, 3methoxytetrahydrothiophene 1,1-dioxide (MESL) is the most interesting one among the 22 synthesized sulfones, because MESL exhibits an oxidation potential at a NMC cathode in the presence of

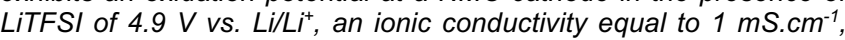
and a low melting point as well as a high boiling point.

\section{Introduction}

For more than two decades, lithium-ion batteries (LiBs) have outclassed other electrochemical energy-storage systems in day life applications such as cell phones or laptops in which classical $4 \mathrm{~V}$ batteries are commonly used. ${ }^{[1-3]}$ However, the need for highenergy density for other applications such as electric vehicles has recently stimulated the search for high energy density batteries, and therefore, the development of high-voltage cathode materials such as $\mathrm{LiCoPO}_{4}, \mathrm{LiNiPO}_{4}, \mathrm{LiMn}_{2} \mathrm{O}_{4}$ or $\mathrm{LiNi} .5 \mathrm{Mn}_{1.5} \mathrm{O}_{4}{ }^{[4-10]}$ Nevertheless, the success of these materials suffers from the lack of compatible electrolytes, i.e. electrolytes that exhibit an anodic stability sufficiently high to achieve a good cycling ability with $5 \mathrm{~V}$ cathode materials.

Liquid and solid electrolytes can be advantageously used in LiBs depending on the targeted applications. Regarding solid electrolyte, the paper published by Varzi et al. ${ }^{[11]}$ draws up a

[a] Prof. A. Chagnes

GéoRessources - UMR CNRS 7359-CREGU

Université de Lorraine

2 Rue du Doyen Roubault 54500, BP 10162, Vandoeuvre-les-Nancy Cedex, France.

[b] Dr. B. Flamme, Dr. M. Haddad. Dr. P. Phansavath, Dr. V.

Ratovelomanana-Vidal

PSL Research University, Chimie ParisTech-CNRS, Institut de

Recherche de Chimie Paris, 11 rue Pierre et Marie Curie, 75005

Paris, France

*Correspondence should be addressed to:

Prof. Alexandre Chagnes (alexandre.chagnes@univ-lorraine.fr) for the investigation of the physicochemical and electrochemical properties of the electrolytes,

Dr. Phannarath Phansavath and Dr. Virginie Ratovelomanana-Vidal for the synthesis of sulfones phannarath.phansavath@chimieparistech.fr (, virginie.vidal@chimie-paristech.fr).

Supporting information for this article is given via a link at the end of the document. recent and complete panorama of challenges and prospects of the role of solid electrolytes for lithium metal batteries, which could be a very competitive technology provided that the safety issues of lithium metal batteries would be fixed. Solid electrolytes including polymeric and inorganic materials may be able to reply to this challenge but a great effort has to be done to increase ionic conductivity and improve the lithium-solid electrolyte interface, especially at low temperature.

In the meantime, many efforts are focused to design new liquid electrolytes. However, these electrolytes cannot be used in lithium metal batteries because of the high reactivity of liquid electrolytes towards lithium metal and dendrites formation. They are presently used in lithium-ion batteries but many improvements must be achieved, especially regarding safety issues and lack of stability at high voltage. The most used liquid electrolytes for LiBs are composed of binary or ternary mixtures of linear and cyclic carbonates in the presence of $1 \mathrm{M} \mathrm{LiPF}_{6}$ (lithium hexafluorophosphate) such as ethylene carbonatedimethyl carbonate (EC-DMC), ethylene carbonate-diethyl carbonate (EC-DEC) or propylene carbonate-ethylene carbonate-dimethyl carbonate (PC-EC-DMC). ${ }^{[12,13]}$ These electrolytes exhibit very good cycling ability at a graphite electrode but also at positive electrodes such as $\mathrm{LiCoO}_{2}$, $\mathrm{LiMn}_{2} \mathrm{O}_{4}$ or $\mathrm{NMC}\left(\mathrm{LiNi}_{1 / 3} \mathrm{Mn}_{1 / 3} \mathrm{Co}_{1 / 3}\right)$ around $4 \mathrm{~V}$ vs. $\mathrm{Li} / \mathrm{Li}^{+}$. Other electrolytes were formulated to achieve particular specifications by using other families of organic dipolar aprotic solvents such as asymmetric alkylcarbonates, ${ }^{[14,15]} \gamma$-butyrolactone in mixture with alkylcarbonates for low-temperature applications ${ }^{[16-18]}$ or ionic liquid-based electrolytes for low and high temperature applications ${ }^{[16-24]}$, sulfone ${ }^{[25]}$, dioxalane ${ }^{26}$ as well as less common solvents such as 3-methyl-2-oxazolidinone ${ }^{[27]}$ and nitriles. ${ }^{[28-30]}$ However, most of the studies reported in the literature are focused on the formulation of new electrolytes for LiBs containing mixtures of commercial solvents, whereas more studies should be dedicated to the synthesis of new solvents and the investigation of their properties.

Flamme et al. ${ }^{[31]}$ have recently published a review on the physicochemical and electrochemical properties of alkylcarbonates, ethers, esters, nitriles, and sulfones. This work showed interesting trends between the chemical structures of these molecules and their physicochemical and electrochemical properties. In particular, the authors emphasize sulfones could be good candidates as solvents for $5 \mathrm{~V}$ electrolytes thanks to their high anodic stability. However, the main drawback for their use in LiBs is their high viscosity and their low ionic conductivity in the presence of lithium salts including $\mathrm{LiPF}_{6}$.

Commercial sulfones such as dimethyl sulfone (DMS), ethyl methyl sulfone (EMS) and tetramethylene sulfone (TMS) were studied for LiBs applications. Nevertheless, their low wettability for Celgard separators and their poor compatibility towards graphite electrodes preclude their use in $4 \mathrm{~V}$ and $5 \mathrm{~V}$ LiBs. In 2002, Xu et al. ${ }^{[32]}$ synthesized 3,3,3-trifluoromethylpropyl sulfone (FMPS, Table 1), but the electrochemical properties of this sulfone were not thoroughly investigated. 
Table 1. Recent sulfones at the laboratory scale for their use in LiBs. ${ }^{[33-35]}$

Name

Only the five sulfones reported in Table 1 were synthesized between 2002 and 2017, ${ }^{[3-35]}$ including three sulfones synthesized in 2017 by Su et al. ${ }^{[35]}$ (trifluoromethyl ethyl sulfone (FMES), trifluoromethyl propyl sulfone (FMPS) and trifluoromethyl isopropyl sulfone (FMIS), see Table 1). Their anodic stability at a platinum electrode and the cycle ability in a full-cell composed of $\mathrm{LiNi}_{0.5} \mathrm{Mn}_{0.3} \mathrm{Co}_{0.2} \mathrm{O}_{2}\left(\mathrm{NMC}_{532}\right)$ and graphite were studied without co-solvent and in mixture with difluoroethylene carbonate (DFEC) or ethyl methyl carbonate (EMC) in the presence of LiPF 6 . It was shown that the addition of fluorine atoms in the structure of sulfones reduces the viscosity and improves the wettability towards Celgard separator. The authors claimed these sulfone-based electrolytes were promising for high-voltage and high-energy lithium-ion batteries. Because only a few papers relate to the synthesis of new sulfones for LiBs application, it is of great interest to synthesize new sulfones to investigate the potential of the sulfone family further. In particular, no sulfone containing ester or ether groups were reported in the literature for their use in LiBs. It seems interesting to study the effect of the addition of such chemical functions in the sulfone structure since esters and ethers are commonly known for their high anodic stability. ${ }^{[31]}$ In the present work, 22 new linear and cyclic sulfones have been synthesized to investigate the effect of fluorine atoms, ethoxy, ester and nitrile moieties on viscosity, thermal stability, ionic conductivity and oxidation potentials of sulfone-based electrolytes containing lithium bis-trifluoromethanesulfonimidate (LiTFSI).

\section{Experimental Section}

\section{Synthesis methods and electrolyte preparations}

The sulfones syntheses were performed according to methods reported in the literature (Scheme 1). ${ }^{[36-38]}$ More informations about the synthesis procedures and sulfone characterizations by NMR and GC-MS are available in the ESI.

1-(Ethylsulfonyl)-2-(2-methoxyethoxy)ethane (EMEES) was obtained starting from diglyme monomethyl ether using a chlorination/alkylation/oxidation sequence (Scheme 1, Reaction 1). 1-Methoxy-2-(methylsulfonyl)ethane (MEMS) was synthesized by the alkylation and oxidation of the $\beta$ mercaptoethanol (Scheme 1, Reaction 2). The same methodology was applied to the synthesis of 4(methylsulfonyl)butanenitrile (MCPS) (Scheme 1, Reaction 3).
Methyl 2-(methylsulfonyl)acetate (MMSA) and ethyl 2(methylsulfonyl)acetate (EMSA) were prepared by divergent alkylation of methyl 2-chloroacetate with sodium methyl sulfinate in methanol or ethanol, respectively (Scheme 1, Reaction 4). 2(Methylsulfonyl)ethyl acetate (MSEA), 2-(methylsulfonyl)ethyl 2,2,2-trifluoroacetate (MSTFA), methyl (2-(methylsulfonyl)ethyl) carbonate (MSEMC), ethyl (2-(methylsulfonyl)ethyl) carbonate (MSDEC), isopropyl (2-(methylsulfonyl)ethyl) carbonate (MSEiPC) were synthesized starting from 2-(methylthio)-ethane1-ol, which was oxidized into sulfone derivatives. The latter were subjected to acetylations and carbonatation reactions in order to access the desired products (Scheme 1, Reaction 5). The same procedures were applied to 3-(methylthio)propan-1-ol to achieve the synthesis of 3-(methylsulfonyl)propyl acetate (MSPA), 3(methylsulfonyl)propyl 2,2,2-trifluoroacetate (MSPTFA), methyl (3-(methylsulfonyl)propyl) carbonate (MSPMC), ethyl (3(methylsulfonyl)propyl) carbonate (MSPEC), and isopropyl (3(methylsulfonyl)propyl) carbonate (MSPiPC).

(1)

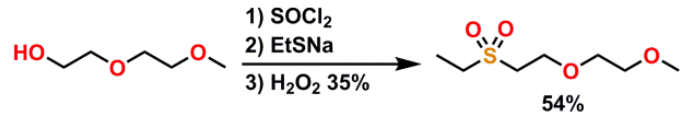

(2)

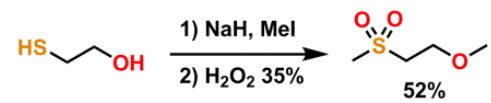

(3)

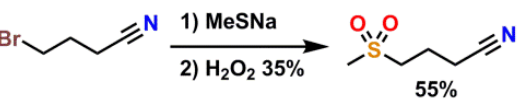

(4)
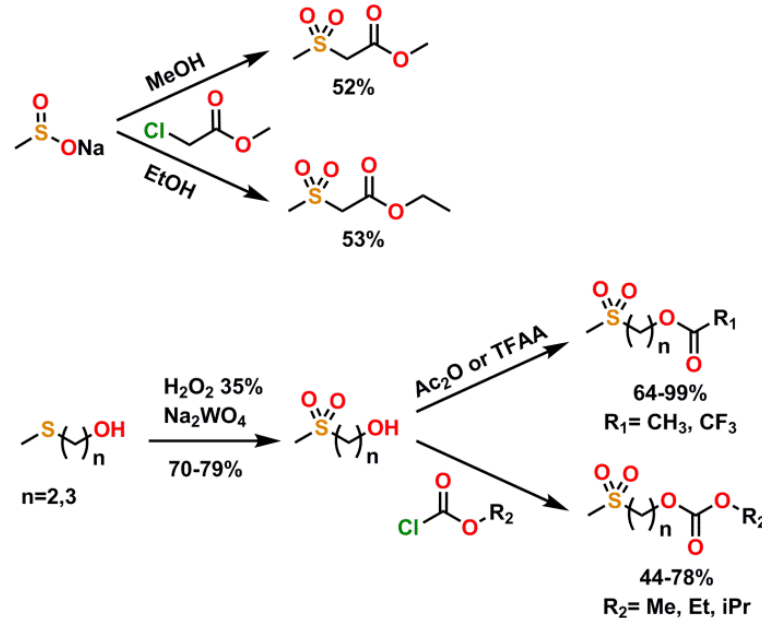

(6)

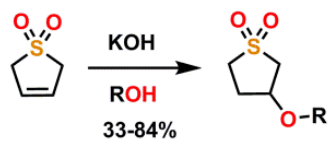

$\mathrm{R}_{2}=\mathrm{Me}, \mathrm{Et}, \mathrm{iPr}$

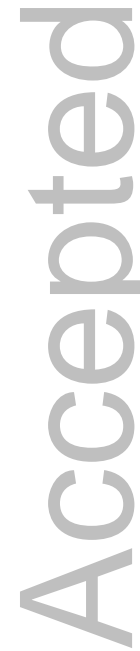

$\mathrm{R}=\mathrm{Me}, \mathrm{Et}, \mathrm{iPr}, \mathrm{C}_{2} \mathrm{H}_{4} \mathrm{OMe}$

(7)
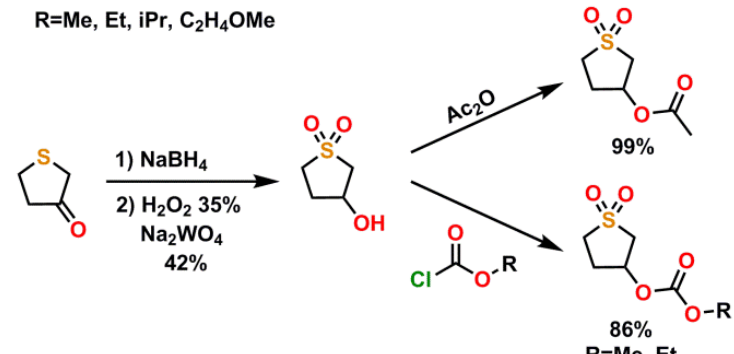

$\mathrm{R}=\mathrm{Me}$, Et

Scheme 1. Synthetic pathways used for bifunctional sulfones synthesis. 
Cyclic sulfones containing an ether group, i.e. 3methoxytetrahydrothiophene 1,1-dioxide (MESL), 3ethoxytetrahydrothiophene 1,1-dioxide (EESL), 3isopropoxytetrahydrothiophene 1,1-dioxide (IESL), 3-(2methoxyethoxy)tetrahydrothiophene 1,1-dioxide (GLSL), were synthesized by treating sulfolene with different alcohols in the presence of $10 \mathrm{~mol} \%$ potassium hydroxide (Scheme 1, Reaction 6). 1,1-Dioxidotetrahydrothiophen-3-yl acetate (ACSL) was synthesized by acetylation whereas 1,1dioxidotetrahydrothiophen-3-yl methyl carbonate (MCSL) and 1,1-dioxidotetrahydrothiophen-3-yl ethyl carbonate (ECSL) were obtained by reacting 3-hydroxysulfolane resulting from reduction and oxidation of dihydrothiophen-3(2H)-one with chloroformates (Scheme 1, Reaction 7).

Appropriate amounts of lithium bis-trifluoromethanesulfonimidate (LiTFSI, Sigma Aldrich, Battery Grade) previously vacuum dried at $120^{\circ} \mathrm{C}$ overnight were mixed with the synthesized sulfones to prepare sulfone-based electrolytes at $1 \mathrm{~mol}^{-\mathrm{L}^{-1}} \mathrm{LiTFSI}$. Water contents in the electrolytes were measured by the coulometric Karl Fisher method by means of the Metrohm KF Titrando titrator. Water content was estimated at 20-30 ppm in the investigated sulfone-based electrolytes. In the case of sulfones exhibiting melting points higher than room temperature, it was possible to determine their ionic conductivities and anodic stabilities in the presence of LiTFSI by heating the electrolyte at $60{ }^{\circ} \mathrm{C}$ followed by slow cooling in order to keep the electrolyte in its liquid state (electrolytes remained liquid at room temperature because of supersaturation phenomena and metastability after LiTFSI solubilisation at high temperature).

\section{Physicochemical characterization}

Melting and boiling points of sulfones were determined by differential scanning calorimetry (DSC). DSC experiments were performed using $40 \mu \mathrm{L}$ aluminum crucibles which were pierced prior to thermal analyses. DSC crucibles were prepared in an argon-filled glovebox containing less than 2 ppm $\mathrm{H}_{2} \mathrm{O}$ and $\mathrm{O}_{2}$. The reference cell was filled with silica. Thermograms were recorded using a Mettler Toledo DSC822e apparatus equipped with a nitrogen gas flow system cooled by liquid nitrogen. To prevent water condensation, a stream of nitrogen was continuously passed around the sample holder. The heating and cooling rates were fixed at $10^{\circ} \mathrm{C} \mathrm{min}-1$.

Density $(\rho)$ and kinematic viscosities ( $v)$ of the synthesized sulfones were determined at $25^{\circ} \mathrm{C}$ by using an Anton Paar DMA $4500 \mathrm{M}$ and an Anton Paar Lovis $2000 \mathrm{ME}$, respectively. The dynamic viscosity $(\eta)$ was deduced from the kinematic viscosity by using the following relationship: $\eta=v / \rho$.

Ionic conductivities were measured at room temperature $\left(23^{\circ} \mathrm{C}\right)$ in an argon-filled glovebox containing less than $2 \mathrm{ppm} \mathrm{H}_{2} \mathrm{O}$ and $\mathrm{O}_{2}$ by using a Mettler Toledo FE30 equipped with an Inlab 741-4 $\mathrm{mm}$ probe (Mettler Toledo).

\section{Electrochemical characterization}

Oxidation potentials were studied by linear and cyclic voltammetry in classical three-electrodes cells using a platinum rotating electrode as working electrode $(1000 \mathrm{rpm})$ and lithium wires as counter and reference electrodes. The same experiments were conducted using only two electrodes in a stainless steel Swagelock system using two glass fibre separators (glass microfiber filter, 691, VWR, $11 \mathrm{~mm}$ diameter), a working electrode of platinum (Goodfellow), glassy carbon or $\mathrm{NMC}\left(\mathrm{LiNi}_{1 / 3} \mathrm{Mn}_{1 / 3} \mathrm{Co}_{1 / 3} \mathrm{O}_{2}\right.$, Aldrich), and a counter/reference electrode of lithium. No major difference was detected on oxidation potential values using either setup. Therefore, the Swagelock system was preferred to determine oxidation potentials in the present work since only small amounts of electrolyte were available (1-2 grams of each sulfone were synthesized). Voltammetry studies were conducted at $5 \mathrm{mV} . \mathrm{s}^{-1}$ and recorded on an Origaflex 500 potentiostat from Origalys Electrochem. Electrochemical measurements and Swagelock assembly were carried out in an argon-filled glovebox containing less than $2 \mathrm{ppm} \mathrm{H}_{2} \mathrm{O}$ and $\mathrm{O}_{2}$.

Anodic stability is one of the most important criteria, especially for high voltage lithium-ion batteries. However, it is difficult to compare rigorously oxidation potentials from the literature because of the lack of uniform evaluation methods and experimental conditions. Oxidation potentials were assayed in the literature by three different methods: (i) determination of oxidation potentials under a constant density current (j), which is arbitrarily chosen, (ii) determination of oxidation potentials by plotting the slope of $j=f(E)$ curves before and after the oxidation, and (iii) determination of the oxidation potential by measuring the leakage current over time of an electrolyte under a constantpotential electrolysis process. In this case, the current intensity reflects the electrochemical instability due to decomposition at a given potential and the anodic potential limit of the electrolyte, as indicated by a sudden jump of the leakage current. ${ }^{12,39}$ In the present paper, another method for determining anodic stability of electrolytes without bias was developed based on the analysis of voltammograms. In this method, the oxidation potential corresponds to the potential for which the slope of the curve $j=f(E)$ takes over a threshold value of 1000 . This slope was determined after reducing the noise of the voltammograms by means of a home-made program developed under Scilab.

\section{Results and Discussion}

\section{Physicochemical properties of new sulfones}

Electrolytes for lithium-ion batteries must exhibit a large thermal stability (low melting point and high boiling point) so that batteries could be used in a large range of temperatures. Furthermore, they must have a low viscosity to ensure high ionic conductivity and to get easier electrolyte penetration into separator and electrode porosity. Last but not least, solvent has to solubilize lithium salt at high concentration, i.e. usually around $1 \mathrm{~mol} \mathrm{~L}^{-1}$ because ionic conductivity is generally at its maximum value at this concentration. ${ }^{40,41}$ Many studies use sulfone-based electrolytes with $\mathrm{LiPF}_{6}$ concentration of about $0.5 \mathrm{~mol} \mathrm{~L}^{-1}$ because $\mathrm{LiPF}_{6}$ cannot be dissolved at $1 \mathrm{~mol} \mathrm{~L}^{-1}$. Conversely, LiTFSI can be more easily solubilized at $1 \mathrm{~mol} \mathrm{~L}^{-1}$ because the charge density borne by $\mathrm{TFSI}^{-}$anion is more delocalized. Therefore, LiTFSI will be used as salt in the present work.

Table 2 gathers boiling point, melting point, density and dynamic viscosity of the 22 sulfones synthesized in the present work. Van der Waals interactions, hydrogen bonding, and molecular shape influence more or less the melting and boiling points. 
Table 2. Physical properties of the synthesized sulfones.

\begin{tabular}{|c|c|c|c|c|c|c|}
\hline Entry & Name & Structure & $\mathrm{T}_{\mathrm{m}}\left({ }^{\circ} \mathrm{C}\right)$ & $\mathrm{T}_{\mathrm{b}}\left({ }^{\circ} \mathrm{C}\right)$ & $\rho\left(\right.$ g.cm $\left.{ }^{-3}\right)$ & $\eta(c P)$ \\
\hline 1 & EMEES & & $<0^{a}$ & 170 & 1.15 & 12.0 \\
\hline 2 & MEMS & & 15 & $\begin{array}{c}97 \text { (2.0 Torr) } \\
261\end{array}$ & 1.21 & 11.5 \\
\hline 3 & MSEA & & 48 & $\begin{array}{c}102-104 \text { (2.0 Torr) } \\
268-270\end{array}$ & $1.24^{\mathrm{b}}$ & $10.9^{*}$ \\
\hline 4 & MSTFA & & -1 & $\begin{array}{c}98-100 \text { (2.0 Torr) } \\
260-263\end{array}$ & 1.94 & 41.9 \\
\hline 5 & MSEMC & & 42 & 292 & $1.30^{*}$ & $15.5^{*}$ \\
\hline 6 & MSDEC & & 21 & 282 & $1.24^{*}$ & $7.4^{*}$ \\
\hline 7 & MSEiPC & & 57 & 244 & & \\
\hline 8 & MSPA & & $<0^{a}$ & 250 & 1.23 & 49.2 \\
\hline 9 & MSPTFA & & 5 & 261 & 1.42 & $>50$ \\
\hline 10 & MSPMC & & 42 & 282 & $1.26^{*}$ & $15.9^{*}$ \\
\hline 11 & MSPEC & & $<0^{a}$ & 262 & 1.24 & $>50$ \\
\hline 12 & MSPiPC & & 21 & 281 & 1.19 & $>50$ \\
\hline 13 & MCPS & & 45 & $\begin{array}{c}138-142 \text { (0.6 Torr) } \\
343-347\end{array}$ & & \\
\hline 14 & MMSA & & 65 & 286 & & \\
\hline 15 & EMSA & & $<0^{a}$ & 260 & 1.25 & 27.5 \\
\hline 16 & MESL & & & $\begin{array}{c}94-96 \text { (0.7 Torr) } \\
280-282\end{array}$ & & \\
\hline 17 & EESL & & 24 & 308 & 1.21 & 19.1 \\
\hline 18 & IESL & & & $\begin{array}{c}105-107 \text { (0.6 Torr) } \\
298-301\end{array}$ & 1.16 & 15.8 \\
\hline 19 & GLSL & & $<0^{\circ}$ & 310 & & \\
\hline 20 & ACSL & & 65 & 248 & & \\
\hline 21 & MCSL & & 92 & 232 & & \\
\hline 22 & ECSL & & 56 & 272 & 1.29 & \\
\hline
\end{tabular}

$\mathrm{T}_{\mathrm{m}}$ : melting point; $\mathrm{T}_{\mathrm{b}}$ : boiling point (at atmospheric pressure except when pressure is given in parentheses); $\rho$ : density at $25^{\circ} \mathrm{C}$ except for values with star $\left({ }^{*}\right)$ for which the temperature is equal to $60^{\circ} \mathrm{C}$; $\eta$ : dynamic viscosity at $25^{\circ} \mathrm{C}$ except for values with star $\left({ }^{*}\right)$ for which the temperature is equal to $60{ }^{\circ} \mathrm{C}$. (a) no crystallization and melting peaks observed by DSC even until $-70 \mathrm{C}^{\circ}$.

If the molecules contributing to the lattice are rigid, compact and symmetrical, they tend to "fit" the best and tend to maximize interactions, which results in higher melting points as it takes more energy to separate the molecules. Examination of Table 2 seems to demonstrate that the presence of ester or carbonate groups results in an increase of the melting point probably because the presence of these chemical functions increases the molecular interactions. ${ }^{[31]}$
Table 2 shows that the high melting point of sulfones is a drawback for their use in electrolyte for LiBs, especially for low temperature applications. Most of the synthesized sulfones exhibit melting points much greater than $0{ }^{\circ} \mathrm{C}$ except for MSTFA, which has a melting point very close to $0{ }^{\circ} \mathrm{C}$ and EMEES, MSPA, MSPEC, EMSA, MESL, IESL and GSL, for which no crystallization and no melting peak were observed by DSC, even at a temperature as low as $-70{ }^{\circ} \mathrm{C}$. The other sulfones, i.e. MEMS, MSDEC, MSPTFA, EESL, are liquid at room 
temperature but their use is limited to temperatures close to 20 ${ }^{\circ} \mathrm{C}$. However, they could be used in LiBs of electric vehicle since the temperature into such LiBs reaches $40{ }^{\circ} \mathrm{C}$. MSEA, MSEMC MSDEC, MSEIPC, MSPMC, MCPS, MMSA, EESL, ACSL, MCSL, ECSL cannot be used alone as electrolytes for LiBs as they are solid at room temperature, and the melting point is greater than the temperature into LiBs of electric vehicle (Table 2). From a practical point of view, these molecules must be mixed with another solvent, which remains liquid withina large range of temperature.

However, it is worth pointing out that the addition of a lithium salt into the solvent usually leads to an important decrease of the melting point of the latter (the decrease of the melting point is usually around $10-20{ }^{\circ} \mathrm{C}$ depending on the solvant and the salt concentration). In spite of the decrease of the melting point in the presence of lithium salt, it would be prefered to add a cosolvent for a use as electrolyte in LiBs.

Boiling points of the synthesized sulfones are very high (more than $200{ }^{\circ} \mathrm{C}$ except for EMEES (Table 2)). Their stability in the liquid state, even at very high temperature, is an advantage for their use in LiBs from a safety point of view. Such high boiling points can be explained by their high molecular weights because the bigger the molecule, the higher the Van der Waals interactions and the higher the boiling point.

Sulfones are known to be viscous compared to other sulfurcontaining compounds such as sulfites, but their anodic stability is usually higher. ${ }^{[331]}$ Cyclic sulfones are generally more viscous than linear sulfones. Table 2 shows that the addition of other groups such as ethers, esters or carbonates is responsible for a sharp increase of the dynamic viscosity because more intermolecular interactions occur. Sulfones containing carbonate groups are generally more viscous than those containing ester groups, which are themselves more viscous than sulfones containing ethers groups (Table 2). The lowest viscosity is obtained for sulfones containing ether functions. The dynamic viscosity is around $12 \mathrm{cP}$ for linear sulfones and $16-19 \mathrm{cP}$ for cyclic sulfones containing an ether function while the dynamic viscosity is usually greater than $30 \mathrm{cP}$ for sulfones containing carbonate or ester groups. Therefore, carbonate and ester functions introduced in the structure of sulfones increase intermolecular interactions and disfavor molecular arrangements. Ionic conductivities of LiTFSI in the synthesized sulfones are gathered in Figure 1. Examination of this Figure shows that ionic conductivities of LiTFSI in the synthesized sulfones are very low (ionic conductivities reported in Figure 1 do not exceed $1 \mathrm{mS} \mathrm{cm}$ $\left.{ }^{1}\right)$. in order to reduce the ohmic drop in LiBs, electrolytes must exhibit high ionic conductivities. High ionic conductivity can be achieved when the lithium salt is highly dissociated in the solvent and ions can move easily in the solvent. Therefore, solvents must have a high dielectric constant and a low viscosity Sulfones are generally characterized by high values of dielectric constants. For instance, ethyl isopropyl sulfone (EIPS) or sulfolane (SL) have a dielectric constant of 55 and 43.3 at $25^{\circ} \mathrm{C}$, respectively. ${ }^{[42,43]}$ Thereby, the poor ionic conductivity of the sulfone-based electrolytes displayed in Figure 1 may be mainly due to the high values of sulfones viscosity.

Electrolytes composed of LiTFSI and sulfones containing ether moiety (MEMS, EMEES MESL, EESL, IESL and GLSL in Figure 1) exhibit higher ionic conductivities than sulfones containing esters or carbonates. Ionic conductivities reach $1.5 \mathrm{mS}_{\mathrm{cm}} \mathrm{cm}^{-1}$ for acyclic sulfones and $1.0 \mathrm{mS} . \mathrm{cm}^{-1}$ for cyclic sulfones. Sulfones with ester functions (MSEA, MSTFA, MSPA, MSPTFA, MMSA, EMSA, and ACSL) exhibit the lowest ionic conductivities, i.e. 0.2-0.3 mS. $\mathrm{cm}^{-1}$, except EMSA which has an ionic conductivity of $0.5 \mathrm{mS} . \mathrm{cm}^{-1}$ likely because this solvent exhibits a slightly lower dynamic viscosity (Table 2).

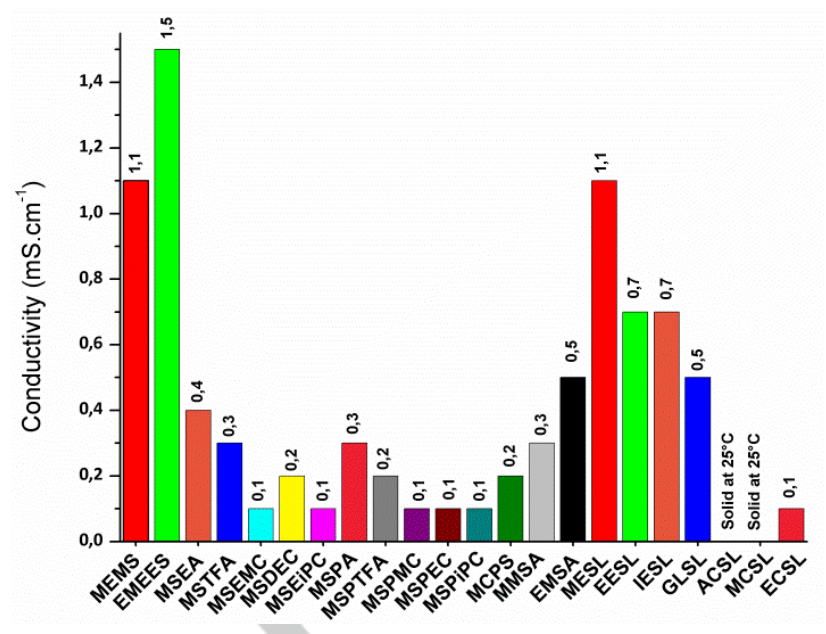

Figure 1. Ionic conductivities at $25{ }^{\circ} \mathrm{C}$ of the synthesized sulfones in the presence of 1 mol.L-1 LiTFSI.

Electrolytes composed of LiTFSI and sulfones containing carbonate moieties (MSEMC, MSDEC, MSEiPC, MSPMC, MSPEC, MSPiPC, MCSL and ECSL) exhibit very low ionic conductivities, i.e. $0.1-0.2 \mathrm{mS} . \mathrm{cm}^{-1}$ at $25^{\circ} \mathrm{C}$. It is clear that such low ionic conductivities represent a drawback for their use in LiBs in the absence of co-solvent. However, good electrochemical properties including formation of a stable passivation layer onto a graphite electrode and high oxidation potential could justify the use of these sulfones in electrolytes for LiBs. More investigations about their electrochemical properties are therefore required

\section{Anodic stability of new sulfones}

Oxidation potentials of electrolytes can strongly vary depending on the nature of the solvent used in the electrolytes, the salt and the electrode. Our group reported important changes in oxidation potentials of sulfur-based electrolytes from $2.9 \mathrm{~V}$ to 5.8 $\mathrm{V}$ vs. $\mathrm{Li} / \mathrm{Li}^{+}$depending on the chemical structure of the solvent. ${ }^{24}$ In particular, electrocatalytic reactions can be responsible for an important drop of the oxidation potential. Such electrocatalytic reactions must be taken into account to evaluate any potential applications of electrolytes for high-density energy LiBs as these reactions diminish considerably the anodic stability of electrolytes. For instance, the oxidation potential of diethylsulfite (DES) in the presence of $\mathrm{LiPF}_{6}$ is dramatically reduced from 4.5 $\mathrm{V}$ to $2.9 \mathrm{~V}$ when oxidation tests are performed at a $\mathrm{LiCoO}_{2}$ electrode usually used in LiBs instead of a platinum electrode. However, other sulfur compounds have been reported that have interesting anodic stability. For instance, 2-(ethylsulfonyl)butane (EsBS) exhibits high oxidation potential, i.e. $5.8 \mathrm{~V} \mathrm{vs.} \mathrm{Li}^{+} / \mathrm{Li}$ at a $\mathrm{LiMn}_{2} \mathrm{O}_{4}$ electrode because no electrocatalytic reactions occur ${ }^{31}$. Likewise, fluoro-2-(methylsulfonyl)benzene (FS), 2(ethylsulfonyl)propane (EiPS), 1-(ethylsulfonyl)-2-methylpropane (EiBS), 2-(ethylsulfonyl)butane (EsBS), (ethylsulfonyl)ethene (EVS), (ethylsulfonyl)cyclopentane (ESCP), 1(propylsulfonyl)propane (DPS), 2-methylthietane 1,1-dioxide (MTS), 3-methyltetrahydrothiophene 1,1-dioxide (3Me-SL) can be considered as relevant solvents for high voltage applications. ${ }^{31}$ For instance, 1-fluoro-2-(methylsulfonyl)benzene (FS), 2-(ethylsulfonyl)propane (EiPS) and 1-

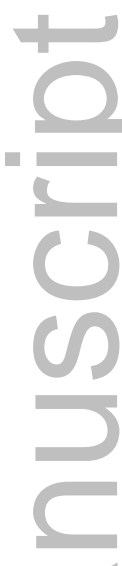

(

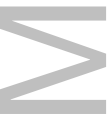

(

(


(propylsulfonyl)propane (DPS) exhibit oxidation potentials of 5.1 $\mathrm{V}, 5.6 \mathrm{~V}$ and $5.7 \mathrm{~V}$ vs. $\mathrm{Li}^{2} \mathrm{Li}^{+}$in the presence of $1 \mathrm{~mol} \mathrm{~L}^{-1} \mathrm{LiTFSI}$ at a platinum electrode, respectively.

Figures 2 and 3 show voltamperograms of the synthesized sulfones reported in Table 2 in the presence of $1 \mathrm{~mol} \mathrm{~L}^{-1}$ LiTFSI at platinum and glassy carbon electrodes. It is interesting to highlight the presence of an anodic wave before the oxidation wall when platinum is used as a working electrode instead of a glassy carbon electrode.

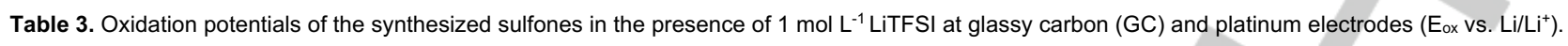

\begin{tabular}{|c|c|c|c|c|c|}
\hline Molecules & Structures & $\mathrm{E}_{\mathrm{ox}}{ }^{\mathrm{a}} \mathrm{Pt}(\mathrm{V})$ & $\mathrm{E}_{\mathrm{ox}}{ }^{\mathrm{b}} \mathrm{Pt}(\mathrm{V})$ & $\mathrm{E}_{\mathrm{ox}}^{\mathrm{a}} \mathrm{GC}(\mathrm{V})$ & $E_{o x^{b}} G C(V)$ \\
\hline EMEES & & 4.0 & 4.9 & 1 & 4.7 \\
\hline MEMS & & 4.3 & 5.0 & I & 4.9 \\
\hline MSEA & & 4.7 & 5.6 & 5.0 & 5.7 \\
\hline MSTFA & & 4.5 & 5.2 & 4.7 & 5.1 \\
\hline MSEMC & & 4.7 & 5.6 & I & 5.5 \\
\hline MSDEC & & 4.7 & 5.4 & 1 & 5.3 \\
\hline MSPA & & 4.4 & 4.9 & I & 4.9 \\
\hline MSPTFA & & 4.2 & 5.2 & 4.5 & 5.1 \\
\hline MSPMC & & 4.4 & 5.3 & 1 & 1 \\
\hline MSPEC & & 4.5 & 5.2 & I & 5.0 \\
\hline MSPiPC & & & 4.9 & 4.5 & 4.9 \\
\hline MCPS & & 4.5 & 5.6 & 4.7 & 5.5 \\
\hline MMSA & & 4.5 & 5.5 & 4.8 & 5.3 \\
\hline EMSA & & 4.0 & 5.0 & I & 5.0 \\
\hline MESL & & 4.2 & 5.1 & 4.5 & 5.1 \\
\hline EESL & & 4.2 & 5.1 & 4.5 & 5.0 \\
\hline IESL & & 4.0 & 5.3 & 4.4 & 5.1 \\
\hline GLSL & & 4.3 & 5.0 & I & 5.0 \\
\hline EESL & & 1 & 5.5 & 1 & 5.5 \\
\hline
\end{tabular}


(a)

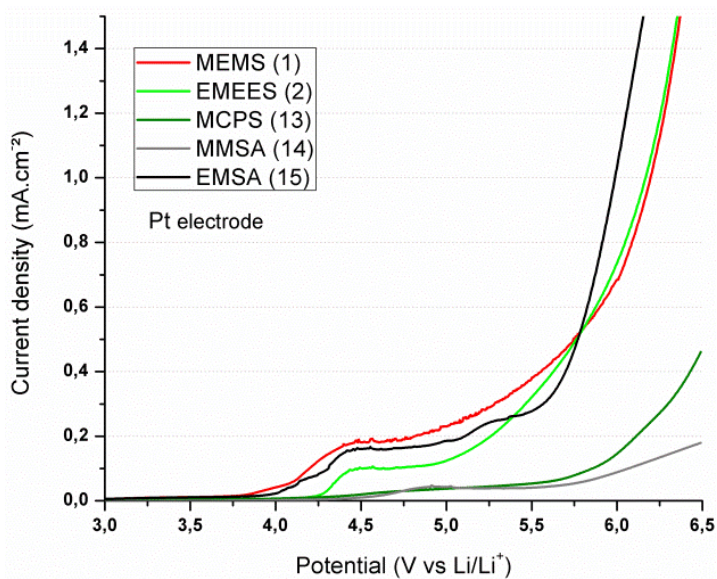

(c)

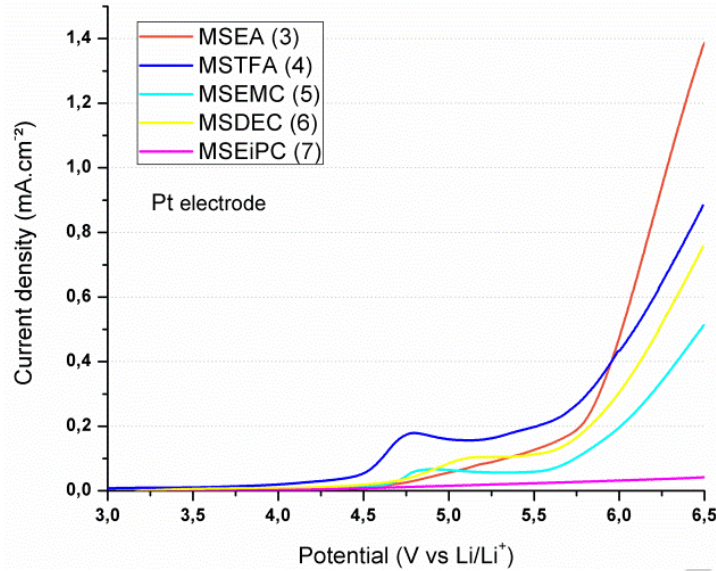

(e)

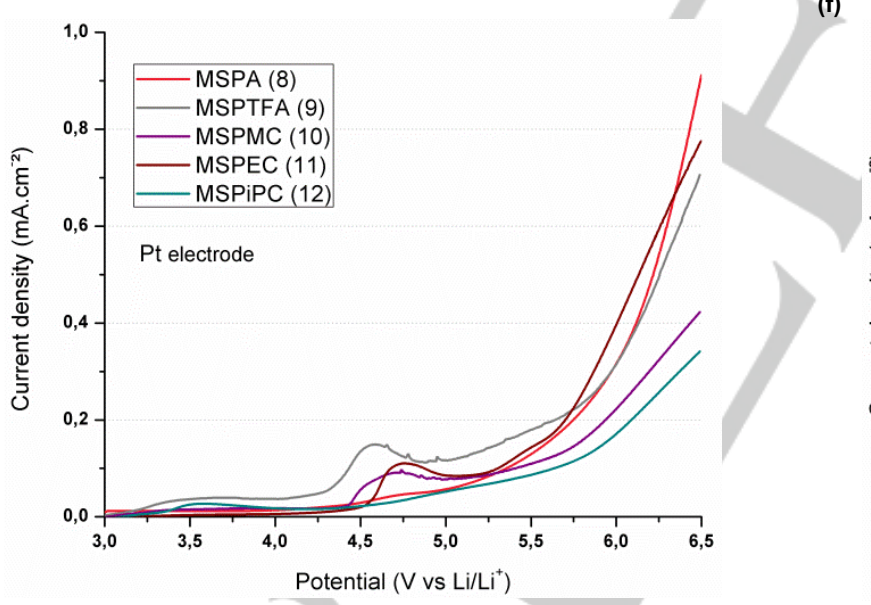

(b)

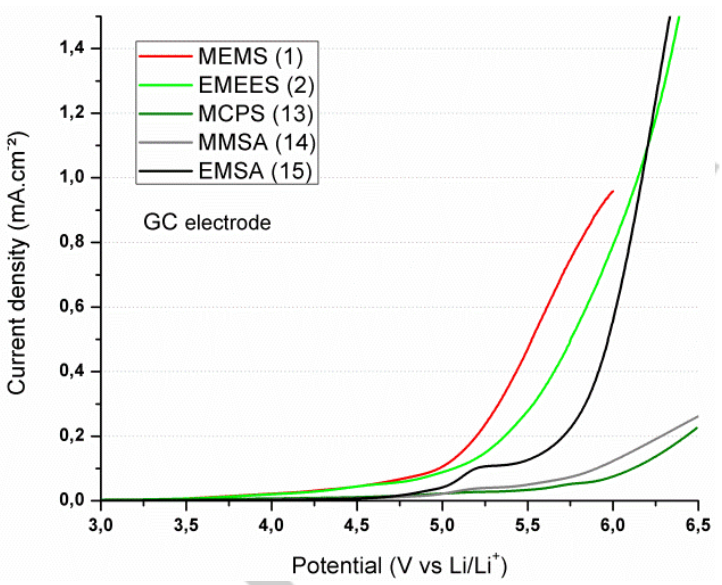

(d)
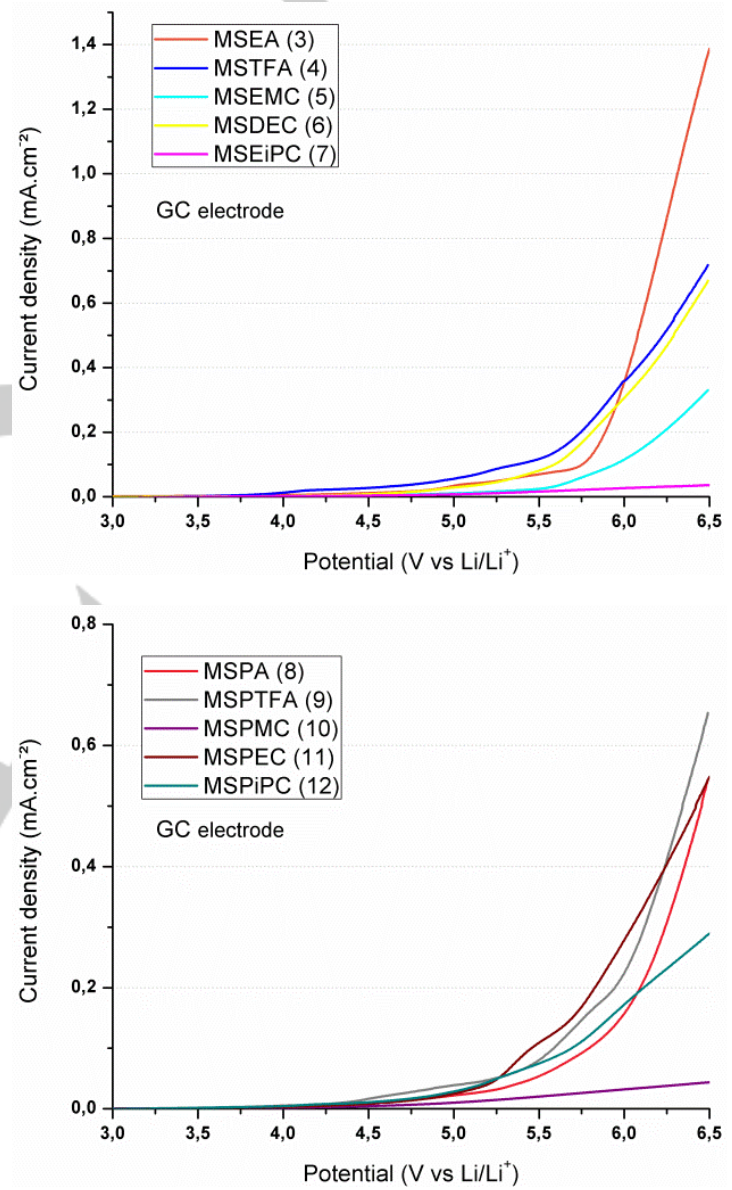

Figure 2. Linear sweep voltamperograms of LiTFSI-based electrolytes containing (a) acyclic sulfones at a platinum electrode (ref. 1, 2, 13-15 in Table 2); (b) acyclic sulfones at a glassy carbon electrode (ref. 1,2,13-15 in Table 2); (c) acyclic sulfones at a platinum electrode (ref. 3-7 from Table 2); (d) acyclic sulfones at a glassy carbon electrode (ref. 3-7 in Table 2); (e) acyclic sulfones at a platinum electrode (Ref. 8-12 in Table 2) and (f) acyclic sulfones at a glassy carbon electrode (8-12 from Table 2). Scan rate is equal to $5 \mathrm{mV} \mathrm{s}^{-1}$.

A two-step mechanism may explain the presence of this anodic wave before the oxidation wall. Such a two-step mechanism is not surprising as the chemical structure of the sulfones contains two functions. Therefore, the anodic wave may be attributed to electrocatalytic oxidation of the solvent.Electrocatalytic reactions onto platinum and glassy carbon electrodes are responsible for a decrease of about $0.8 \mathrm{~V}$ and $0.6 \mathrm{~V}$ vs. $\mathrm{Li}^{2} / \mathrm{Li}^{+}$of the anodic stability of the electrolytes, respectively (Table 3 ). All sulfones undergo electrocatalytic reaction onto platinum and glassy carbon electrodes but they are more sensitive to electrocatalytic reactions onto platinum electrode.

Sulfones containing ether functions, i.e. MEMS and EMEES, exhibit lower anodic stability at a glassy carbon electrode than sulfones containing ester or nitrile groups $(5.0 \mathrm{~V}$ and $4.9 \mathrm{~V}$ vs. $\mathrm{Li} / \mathrm{Li}^{+}$against $5.6 \mathrm{~V}, 5.5 \mathrm{~V}, 5.6 \mathrm{~V}$ vs. $\mathrm{Li}^{2} \mathrm{Li}^{+}$for MSEA, MMSA, 
MCPS, respectively). There is no significant change in the anodic stability when cyclic sulfones are replaced by linear sulfones and no correlation can be deduced between the chemical structure of sulfones and their anodic stabilities. The anodic stability at a glassy carbon electrode and a platinum electrode follows the same trend but it is higher at a glassy ether groups. Furthermore, no significant change in the anodic stability of the sulfones is achieved when an electronegative group such as nitrile or fluorine is added in the chemical structure of the sulfones.

Figure 4 shows the linear sweep voltamperograms of MESL, IESL, MCPS and MSEA at a NMC electrode as well as the corresponding oxidation potentials. The anodic wave located at about $4 \mathrm{~V}$ vs. $\mathrm{Li} / \mathrm{Li}^{+}$corresponds to lithium deinsertion from NMC as previously reported: ${ }^{[44]}$

$$
\mathrm{LiNi}_{1 / 3} \mathrm{Mn}_{1 / 3} \mathrm{Co}_{1 / 3} \mathrm{O}_{2} \rightarrow \mathrm{Li}_{1-x} \mathrm{Ni}_{1 / 3} \mathrm{Mn}_{1 / 3} \mathrm{Co}_{1 / 3} \mathrm{O}_{2}+\mathrm{xLi}^{+}+\mathrm{xe}^{-}
$$

After this wave, the anodic wall attributed to the electrolyte oxidation is observed. The noisy signal observed for MSEA and MCPS when the anodic current suddenly increases is typical of gas formation due the electrolyte oxidation. The oxidation potential of MESL, IESL, MCPS and MSEA in the presence of 1 mol L $\mathrm{L}^{-1}$ LiTFSI deduced

(a)

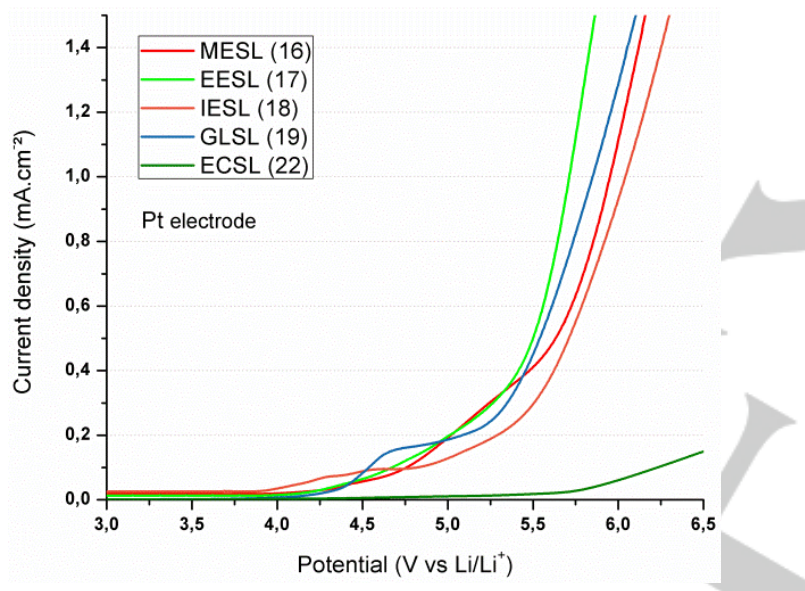

(b)

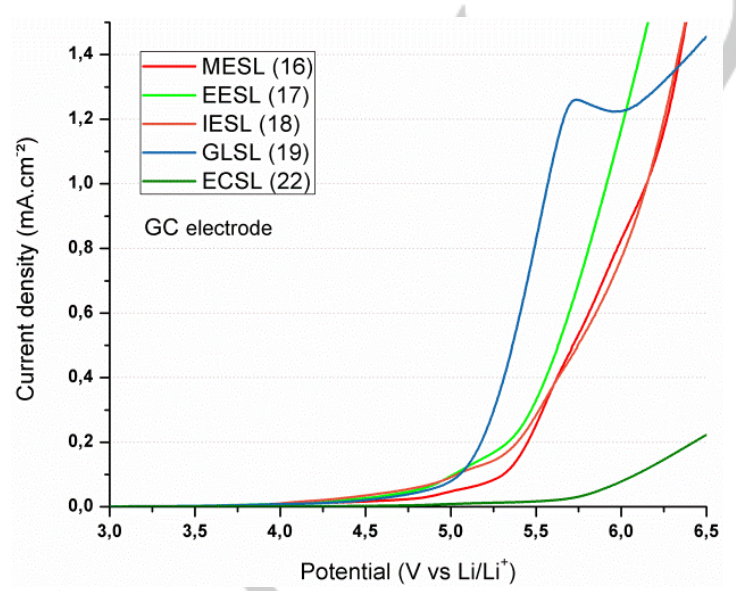

Figure 3 Linear sweep voltamperograms of LiTFSI-based electrolytes containing the cyclic sulfones reported in Table 2 at (a) a platinum electrode and (b) a glassy carbon electrode (scan rate $=5 \mathrm{mV} . \mathrm{s}^{-1}$ ). carbon electrode. EMEES is the less stable electrolyte and the best anodic stability is achieved with MSEA.Examination of Table 3 shows that the anodic stability of sulfones containing carbonate and ester moieties is of the same order and greater than the anodic stability of

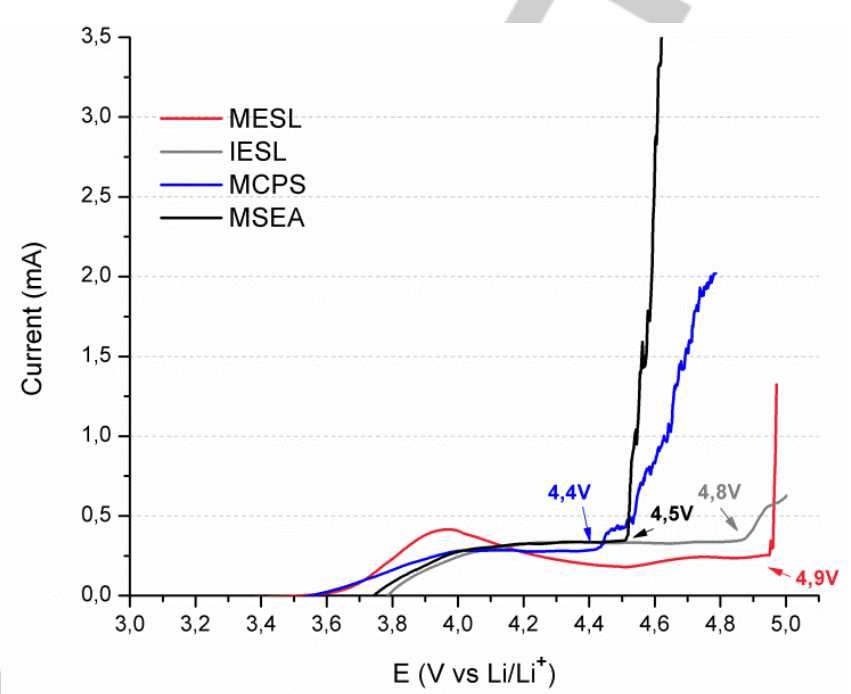

Figure 4 Linear sweep voltamperograms at a NMC electrode for LiTFSI-based electrolytes containing the sulfones \#3,13,16 and 18 in Table 2 (scan rate= $0.05 \mathrm{mV} \mathrm{s}^{-1}$ ).

from Figure 4 are $4.9 \mathrm{~V}, 4.7 \mathrm{~V}, 4.4 \mathrm{~V}$ and $4.5 \mathrm{~V}$ vs. $\mathrm{Li}^{2} \mathrm{Li}^{+}$ respectively. A slight decrease of the anodic stability is observed when the glassy carbon electrode or the platinum electrode is replaced by NMC because of electrocatalytic reactions. The electrocatalytic reactivity of sulfones onto NMC electrode is therefore slightly more important than onto platinum or glassy carbon electrodes.

It is interesting to highlight that MESL exhibits the best anodic stability at a NMC cathode in the presence of LiTFSI among the investigated sulfones. Such a high anodic stability allows to envisage its use in electrolyte for high-voltage LiBs. In addition to the electrochemical properties of MESL, its physicochemical properties are compatible with a use in LiBs, especially because the ionic conductivity of this solvent in the presence of $1 \mathrm{~mol}^{-\mathrm{L}^{-1}}$ LiTFSI is high enough $\left(1 \mathrm{mS} . \mathrm{cm}^{-1}\right.$ at $\left.25^{\circ} \mathrm{C}\right)$ and this solvent remains liquid within a large range of temperatures (no freezing peak was observed by DSC down to $-70^{\circ} \mathrm{C}$ ).

\section{Conclusions}

For the first time, bifunctional sulfones containing ether, ester and carbonate moieties have been synthesized to investigate their physicochemical and electrochemical properties for lithiumion batteries. The main objective of this work was focused on the search for alternative electrolytes for $5 \mathrm{~V}$ batteries, i.e. electrolytes exhibiting high anodic stability. Bifunctional sulfones are generally more viscous than classical sulfones reported in the literature for LiBs applications, they have higher melting points and their ionic conductivities in the presence of LiTFSI do not exceed $1.2 \mathrm{mS} \mathrm{cm}^{-1}$ at $25^{\circ} \mathrm{C}$ because of their high viscosity. Nevertheless, ionic conductivity is high enough to envisage their use as electrolyte in LiBs alone or in the presence of a cosolvent if their high melting point is too high to be liquid near 
room temperature. All of the synthesized sulfones have high boiling points, which brings interesting safety properties to bifunctional sulfones. Last but not least, bifunctional sulfones exhibit high anodic stability despite electrocatalytic reactions onto platinum and glassy electrodes as well as NMC cathode materials. The anodic stabilities of sulfones containing carbonate and ester moieties are of the same order and greater than the anodic stabilities of sulfones containing ether groups. It is difficult to give a general trend to find sulfone exhibiting high anodic stability because the oxidation degradation of electrolytes depends on the nature of the solvent, the salt and the electrode material caused by electrocatalytic reactions. However, it is also possible to play on salt:solvent molar ratio to improve the electrolyte stability beside the chemical structure of the molecules.

Among the different bifunctional sulfones synthesized in the present work, MESL seems to be the most interesting one for high energy density LiBs because the oxidation potential of this sulfone in the presence of LiTFSI onto NMC cathode material reaches $4.9 \mathrm{~V}$ vs. $\mathrm{Li} / \mathrm{Li}^{+}$. The cyclability of MESL onto NMC and graphite electrode will be further investigated.

\section{Acknowledgements}

We thank the Agence Nationale de la Recherche (ANR DEVEGA, 2014-2019 for a financial support, B. F.). We also thank Dr Céline Fosse for performing GC-MS analyses.

Keywords: Anodic stability; Electrolyte; Lithium ion batteries; Oxidation; Solvent; Sulfone.

\section{References}

[1] J.R. Owen, Chem. Soc. Rev., 1997, 26, 259-267.

[2] B. Scrosati, J. Garche, J. Power Sources 2010, 195, 2419-2430.

[3] J. B. Goodenough, J. B., Energy Environ. Sci. 2014, 7, 14-18

[4] N. Nitta, F. Wu, J.T. Lee, G. Yushin, Mater. Today, 2015, 18, 252-264.

[5] J. Wolfenstine, J. Allen, J. Power Sources, 2005, 142, 389-390.

[6] J. Yu, K. M. Rosso, J. Liu, J. Phys. Chem. C, 2011, 115, 25001-25006.

[7] C. A. J. Fisher, V. M. H. Prieto, M. S. Islam, Chem. Mater., 2008, 20, 5907-5915.

[8] J. L. Allen, T. R. Jow, J. Wolfenstine, J. Power Sources, 2011, 196, 8656-8661.

[9] M. Zhong, A. Bonakdarpour, M. Zhang, Y. Gao, J. R. Dahn, J. Electrochem. Soc., 1997, 144, 205-213.

[10] R. Santhanam, B. Rambabu, J. Power Sources, 2010, 195, 5442-5451.

[11] A. Varzi, R.Raccichini, S. Passerini, B. Scrosati, J. Mater. Chem. A 2016, 4, 17251-17259.

[12] A. Chagnes, in Lithium Process Chemistry: Resources, Extractions, Batteries and Recycling (Eds. Chagnes, J. Swiatowska), Elsevier, Amsterdam, 2015, pp. 41-80.

[13] A. Chagnes, J. Swiatowska, in Lithium lon Batteries - New Developments, (Ed llias Belharouak), InTech, 2012, pp. 145-172.

[14] I. Geoffroy,. A. Chagnes, B. Carré, D. Lemordant, P. Biensan, S. Herreyre, J. Power Sources, 2002, 112, 191-198.

[15] Z. Zhang, L. Hu, H. Wu, W. Weng, M. Koh, P. C. Redfern, L. A. Curtiss, K. Amine, Energy Environ. Sci., 2013, 6, 1806-1810.
[16] A. Chagnes, C. Mialkowski, B. Carré, D. Lemordant, V. Agafonov, P. Willmann, J. Phys. IV, 2001, 11, 10-27.

[17] A. Chagnes, H. Allouchi, B. Carré, G. Oudou, P. Willmann, D. Lemordant, J. Appl. Electrochem., 2003, 33, 589-595.

[18] A. Chagnes, B. Carré, P. Willmann, R. Dedryvère, D. Gonbeau, D. Lemordant, J. Electrochem. Soc., 2003, 159, A1255-A1261.

[19] A. Chagnes, M. Diaw, B. Carré, P. Willmann, D. Lemordant, J. Power Sources, 2005, 145, 82-88.

[20] M. Diaw, A. Chagnes, B. Carré, P. Willmann, D. Lemordant, J. Power Sources, 2005, 146, 682-684.

[21] E. Markevich, V. Baranchugov, D. Aurbach, Electrochem. Commun., 2006, 8, 1331-1334.

[22] V. Borgel, E. Markevich, D. Aurbach, G. Semrau, M. Schmidt, J. Power Sources, 2009, 189, 331-336.

[23] D. M. Poper, T. Evans, K. Leung, T. Watkins, J. Olson, S. C. Kim, S. S. Han, V. Bhat, K. H. Oh, D. A. ButtryandS.-H. Lee, Nat. Commun., 2015, 6, 7230-7239.

[24] G. A. Giffin, J. Mater. Chem. A, 2016, 4, 13378-13389.

[25] A. Birrozzi, N. Laszczynski, M. Hekmatfar, J. Von Zamory, G.A. Giffin, S. Passerini, J. Power Sources 2016, 325, 525-533.

[26] R. Raccichini, J. W. Dibden, A. Brew, J.R. Owen, N. Garcia-Araez, J. Phys. Chem. B, 2018, 122, 267-274.

[27] L. Gzara, A. Chagnes, B. Carré, M. Dhahbi, D. Lemordant, J. Power Sources, 2006, 156, 634-644.

[28] E. Nanini-Maury, J. Swiatowska, A. Chagnes, S. Zanna, P. Tran-Van, P. Marcus, M. Cassir, Electrochim. Acta, 2014, 115, 223-233.

[29] Y. Abu-Lebdeh, I. Davidson, J. Electrochem. Soc., 2009, 156, A60-A65.

[30] H. Duncan, N. Salem, Y. Abu-Lebdeh, J. Electrochem. Soc., 2013, 160, A838-A848.

[31] B. Flamme, G. Rodriguez Garcia, M. Weil, M. Haddad, P. Phansavath, V. Ratovelomanana-Vidal, A. Chagnes, Green Chem., 2017, 19, 18281849.

[32] K. Xu, C. A. Angell, J. Electrochem. Soc., 2002, 149, A920-A926.

[33] C.-C. Su, M. He, P. Redfern, L. A. Curtiss, C. Liao, L. Zhang, A. K. Burrell, Z. Zhang, ChemElectroChem., 2016, 3, 790-797.

[34] X.-G, Sun, C. A. Angell, Solid State Ion. 2004, 175, 257-260.

[35] C.-C. Su, M. He, P. C. Redfern, L. A. Curtiss, , I. A. Shkrob, Z. Zhang, Energy Environ. Sci. 2017, 10, 900-904.

[36] B. Loev, J. Org. Chem., 1961, 26, 4394-4399.

[37] J. H. Dodd, C. F. Schewender, J. Gray Nunez, J. Heterocyclic Chem. 2009, 27, 1453-1456.

[38] C. Yang, Q. Jin, H. Zhang, J. Liao, J. Zhu, B. Yu, J. Deng, Green Chem., 2009, 11, 1401-1405.

[39] L. Hu, Z. Zhang, K. Amine, J. Power Sources, 2013, 236, 175-180.

[40] A. Chagnes, B. Carré, D. Lemordant, P. Willmann, Electrochim. Acta, 2001, 46, 1783-1791.

[41] A. Chagnes, B. Carré, D. Lemordant, P. Willmann, J. Power Sources, 2002, 109, 203-213.

[42] K. Chiba, T. Ueda, Y. Yamaguchi, Y. Oki, F. Shimodate, K. Naoi, J. Electrochem. Soc. 2011, 158, A872-A882.

[43] S. Li, W. Zhao, Z. Zhou, X. Cui, Z. Shang, H. Liu, D. Zhang, ACS Appl. Mater. Interfaces, 2014, 6, 4920-4926.

[44] C. M. Julien, A. Mauger, K. Zaghib, H. Groult, Inorganics, 2014, 2, 132154. 
Entry for the Table of Contents (Please choose one layout)

\section{Introduction}

\section{Experimental Section}

Synthesis methods and electrolyte preparations

Physicochemical characterization

Electrochemical characterization

\section{Results and Discussion}

Physicochemical properties of new sulfones

Anodic stability of new sulfones

\section{Conclusions}

\section{Acknowledgements}

\section{References}

\section{ARTICLE}

Physicochemical and electrochemical properties of new sulfones synthesized at the laboratory scale have been investigated.

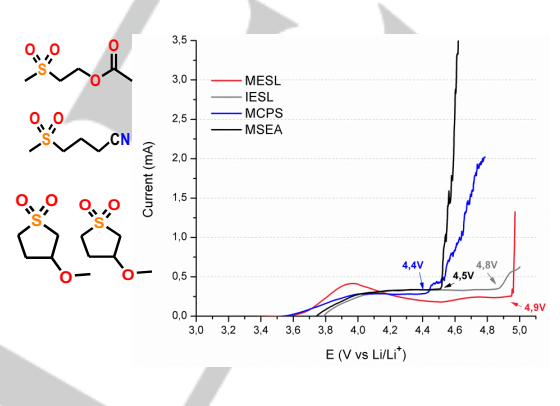

B. Flamme, M. Haddad, $P$ Phansavath, ${ }^{*} V$. RatovelomananaVidal, * and A. Chagnes*

Page No. - Page No. Anodic stability of new sulfonebased electrolytes for lithium-ion batteries 